$12-2011$

\title{
Obstetricians and Violence against Women
}

Sonya Charles

Cleveland State University, s.charles07@csuohio.edu

Follow this and additional works at: https://engagedscholarship.csuohio.edu/clphil_facpub

Part of the Bioethics and Medical Ethics Commons, Obstetrics and Gynecology Commons, and the Philosophy Commons

How does access to this work benefit you? Let us know!

\section{Publisher's Statement}

This is an Accepted Manuscript of an article published by Taylor \& Francis in the American Journal of Bioethics in 2011, available online: 10.1080/15265161.2011.623813.

\section{Original Citation}

Charles, S. (2011). Obstetricians and violence against women. American Journal Of Bioethics, 11(12), 51-56. doi:10.1080/15265161.2011.623813

This Article is brought to you for free and open access by the Philosophy \& Comparative Religion Department at EngagedScholarship@CSU. It has been accepted for inclusion in Philosophy \& Comparative Religion Department Faculty Publications by an authorized administrator of EngagedScholarship@CSU. For more information, please contact library.es@csuohio.edu. 


\title{
Obstetricians and Violence Against Women
}

\section{Sonya Charles, Cleveland State University}

\begin{abstract}
I argue that the American Congress of Obstetricians and Gynecologists (ACOG), as an organization and through its individual members, can and should be a far greater ally in the prevention of violence against women. Specifically, I argue that we need to pay attention to obstetrical practices that inadvertently contribute to the problem of violence against women. While intimate partner violence is a complex phenomenon, I focus on the coercive control of women and adherence to oppressive gender norms. Using physician response to alcohol use during pregnancy and court-ordered medical treatment as examples, I show how some obstetrical practices mirror the attitudes of abusive men insofar as they try to coercively control women's behavior through manipulation and violence. To be greater allies in the prevention of violence against women, obstetricians should stop participating in practices that inadvertently perpetuate violence against women.
\end{abstract}

Keywords: alcohol, cesarean, courts, obstetrics, pregnancy, violence

The American Congress of Obstetricians and Gynecologists (ACOG) has been working to address violence against women for a number of years. Its primary response is to educate physicians and encourage screening and intervention. It dedicates an entire section of the organization's website to the problem of violence against women (American Congress of Obstetricians and Gynecologists 2010), and the section includes educational materials (such as statistics about violence and a slideshow that specifically addresses the problem of violence during pregnancy), resources (e.g., groups working to end violence against women, support resources for victims of abuse), and screening tools. For at least 10 years, ACOG has advocated for physicians to routinely screen all their patients for the risk of violence and offer appropriate intervention strategies when such patients are identified.

While these are laudable goals and efforts, I argue that ACOG (as an organization and through its individual members) can and should be a far greater ally in the prevention of violence against women. ${ }^{1}$ Specifically, I argue that we need to pay attention to other obstetrical practices that inadvertently contribute to the problem of violence against women. In the next section, I take a very brief look at the behaviors and tactics of abusive men. While intimate partner violence is a complex phenomenon, I focus on the coercive control of women and adherence to oppressive gender norms. Using physician response to alcohol use during pregnancy and court-ordered medical treatment as examples, I show how some obstetrical practices mirror the attitudes of abusive men insofar as they try to coercively control women's behavior through manipulation and violence. To be greater allies in the prevention of violence against women, obste- tricians should stop participating in practices that inadvertently perpetuate violence against women.

\section{CHARACTERISTICS OF ABUSIVE MEN}

Those who research domestic violence note that men who abuse women generally have patriarchal and misogynistic attitudes toward women and they use these attitudes to justify their violence against women (van Wormer and Roberts 2009, 5). For example, consider Julia Hall's study of teen boys in Canal Town. The boys considered patriarchal dominance their birthright and this attitude was used to justify violence against women. Here is Robbie commenting on how he envisions his future family:

I'd like a big house, a wife, and a bunch of kids, I guess. ... I'll be making a lot of money, hopefully, so my wife won't work. She'll take care of the kids, cook, clean. She'll pick up the pizza when I order it too. She won't complain too.... I wouldn't want her to work.... She should be home raising the kids.... It's all part of the contract of being married...the wife takes care of the husband and the husband gets some free time. (Hall 2000, 476)

Later, Robbie uses these same oppressive gender norms to justify his father abusing his mother:

There's no priority problems in our house except my dad is crabby. They [father and mother] will yell for a couple of minutes and then quit. ... He pushes her around a little bit, like if the house gets messy or the food is burned. ... My dad apologizes to her though. He is usually true when he says he's sorry. It's just that she doesn't always do what she's supposed to. (Hall 2000, 478)

1. Also, studies show that screening and intervention strategies have not been implemented as well as they could be (Chambliss, Bay, and Jones 1995; Chez and Horan 1999; Frank et al. 2006; Horan et al. 1998; Parsons et al. 1995).

Address correspondence to Sonya Charles, Ph.D., Cleveland State University, Philosophy, 2121 Euclid Avenue, Cleveland, OH 44115, USA. E-mail: s.charles07@csuohio.edu 
Here we see a direct connection between ideals of male supremacy, control of women, and violence against women. In Hall's study of young men with abusive tendencies, this was a common theme: "As they described family relations, they elaborated on an ethos of male supremacy and control as they consistently discussed violence in the home in the form of men hitting women" (Hall 2000, 478). Therefore, gender domination and coercive control of women's behavior are key factors in intimate partner violence.

In what follows, I explore how some obstetrical practices also exhibit these characteristics. I readily admit that most obstetricians are caring professionals who are genuinely trying to improve women's health. However, in some obstetrical practices, we see a disturbing likeness to the behaviors and tactics of abusive men. Specifically, abusive men use manipulation, intimidation, and violence to control women's behavior (van Wormer and Roberts 2009). In the next two sections, I show how some obstetrical practices also use manipulation, intimidation, and violence to control women's behavior. In both cases, these controlling behaviors are founded on or rationalized by oppressive gender norms.

\section{ALCOHOL USE DURING PREGNANCY}

In this and the following section, I take a more in-depth look at two issues-obstetrician response to alcohol use during pregnancy, ${ }^{2}$ and the continuing problem of forced medical treatment for pregnant women. My argument is that the attitudes toward pregnant women reflected in these practices are similar to those of abusive men insofar as they use manipulation and violence to control women's behavior. I believe most obstetricians are caring professionals who are trying to do what is best for their patients. However, the obstetrical community needs to consider the implications of some obstetrical practices. Even though their intentions are very different from those of abusive men, my claim is that these obstetrical practices inadvertently perpetuate violence against women by using coercion to control pregnant women's behavior. Thus, these obstetrical practices are disturbingly similar to the behavior of abusive men and should stop.

While there is much evidence supporting a connection between alcohol and certain birth anomalies, this connection is somewhat mysterious. ${ }^{3}$ Research shows that even among alcoholic women, only 5\% will have a child affected with fetal alcohol syndrome (FAS). Also, FAS is most common among populations with other factors that also con-

2. Clearly, other physicians also promote the abstinence-only approach to alcohol during pregnancy. In fact, pediatricians are often more dogmatic than obstetricians in relation to this topic. However, in this article, I only discuss obstetricians' role in promoting this view.

3. My argument in this section draws heavily on the work of Elizabeth Armstrong. Her sociological account of shifting attitudes toward pregnant women and alcohol and the creation of fetal alcohol syndrome was invaluable (Armstrong 2003). While Armstrong takes a more nuanced approach, I make a more pointed argument about the implications of this practice. tribute to poor birth outcomes, such as poor nutrition, lack of prenatal care, smoking, and high stress levels (or conditions often associated with poverty). Given these discrepancies, researchers are unclear whether alcohol directly causes anomalies or if it is the way the body breaks down the alcohol (some have speculated a genetic connection) or if it is comorbidity factors that make FAS possible. In addition to these ambiguities, there is no clear consensus about the level of alcohol consumption and FAS. While it is true that no safe amount has been established through scientific research (and given the other factors just listed, any "safe" amount would probably vary from woman to woman), numerous studies have shown that for most healthy women light (and probably moderate) drinking will have no effect on fetal outcomes (Armstrong 2003; Gavaghan 2009).

Despite the ambiguities just outlined, ever since FAS was established as a legitimate disorder, ${ }^{4}$ physicians have recommended complete abstinence for all pregnant women. ${ }^{5}$ This abstinence-only approach is paternalistic and suggests that pregnant women's behavior should be regulated. In "You Can't Handle the Truth," Gavaghan sums it up this way:

To continue preaching total abstinence because of a fear that women will misunderstand the truth, or regard a reassuring message about low-level consumption as a "green light" for unrestrained overindulgence, is patronising and paternalistic to a degree that is hard to reconcile with any real respect for autonomy and informed decision-making. (Gavaghan 2009, 303)

Instead of giving women accurate information and allowing them to make an informed decision, obstetricians intentionally overstate the risks of alcohol use. In other words, they manipulate women in an attempt to control their behavior. My principle contention is that by ignoring the ambiguity surrounding FAS and advocating complete abstinence for all pregnant women, obstetricians try to coercively control women's behavior through control of medical information and their social authority.

In addition to specific medical advice, ACOG uses its social authority to reinforce the abstinence-only approach as a cultural norm. For example, in 2008, ACOG released a press release in relation to a morning news show that dared to ask the question: "Can Pregnant Women Drink Alcohol in Moderation?" In this press release, ACOG reiterated the abstinence-only approach, stating that the program "has created tremendous confusion among women about the safety of drinking alcohol during pregnancy." In

4. The first articles on FAS appeared in 1973 and 1974; however, given the lax attitudes about alcohol and pregnancy held by obstetricians at the time, it took a number of years and some debate before FAS was generally acknowledged as a legitimate disorder (Armstrong 2003)

5. Again I want to emphasize that I am discussing obstetricians as a profession and how they have shaped public attitudes and policy through the creation of this disease. The attitudes of individual obstetricians vary greatly. Many individual practitioners remain more agnostic about alcohol during pregnancy and continue to simply encourage moderation. 
response, ACOG "strongly urges women not to ignore the public health warnings associated with consuming alcohol while pregnant" (American Congress of Gynecologists and Obstetricians 2008). Here ACOG as an organization is using its social authority to reinforce its paternalistic stance on alcohol use during pregnancy. By using its social authority in this way, ACOG is doing two things. First, it is trying to control the information women receive by attempting to discredit any dissenting information. Second, it is using intimidation (i.e., using its social authority) to help create norms that conform to its view.

Thus, in the abstinence-only campaign, we see parallels to the tactics used by abusive men. Abusive men expect women to accept their authority and resist challenges to that authority. Abusive men also resent the input of outsiders they see as "on the side of" the partner (i.e., the partner's family and friends). As such, they often work to isolate the woman from those support networks or dissenting opinions (Goodrum, Umberson, and Anderson 2001). Here we see ACOG expecting women to not question their stance on this issue and trying to silence or discredit those who do.

Furthermore, this practice of promoting complete abstinence for all pregnant women is based more on oppressive gender norms than on sound empirical evidence. In "Risk and the Pregnant Body," Lyerly and her colleagues show how physicians have a tendency to overstate fetal risk (even in opposition to reassuring empirical evidence) when the intervention is for the benefit of the mother, but the tendency is to understate fetal risk when the intervention is for the benefit of the fetus or a male partner.

The idea of imposing any risk on the fetus, however small or theoretical, for the benefit of the pregnant woman's interest has become anathema. A second cup of coffee, the occasional beer, the medication that treats a woman's severe allergies but brings a slight increase in the risk of cleft palate, the particular SSRI that best treats a woman's severe recalcitrant anxiety disorder but brings a small chance of heart defects—all are off limits, or nearly so, to a "good mother." (Lyerly et al. 2009, 40, emphasis in original)

We do not require the same level of self-sacrifice or vigilance from men. For example, there is some reason to believe that sexual intercourse while pregnant could pose a risk to the pregnancy / fetus, but the empirical evidence is ambiguous as to the nature of this risk. Despite this potential risk and lack of information, "Most Web sites and doctors reassure that intercourse is safe during pregnancy and advise women to go ahead if they are so inclined" (Lyerly et al. $2009,40)$. So, women must not take any risk-no matter how small or unsupported-for their pleasure or comfort, but when the question is one of men's pleasure, the risks are ignored or women are encouraged to take them. ${ }^{6}$

6. Clearly this assumes a heterosexual relationship; however, since Lyerly and her colleagues discuss this in relation to heterosexual couples, I do as well. Also, at least some of the potential risk assumes heterosexual relations (e.g., prostaglandins in sperm).
By comparing attitudes toward paternal versus maternal risk, we see how the abstinence-only campaign is based more on problematic gender norms than sound empirical evidence. Specifically, obstetricians try to coerce women into fulfilling the role of the "good mother." "Good" mothers will sacrifice anything for their fetus/baby/children while "bad" mothers selfishly indulge in their own pursuits. ${ }^{7}$ In this way, the practice of promoting complete abstinence for all pregnant women is part of a web of clinical practices built on oppressive gender norms.

In sum, my argument is that obstetrician response to alcohol use during pregnancy shows a disturbing likeness to the behaviors and tactics of abusive men. Obstetricians try to coercively control women's behavior through manipulation (i.e., controlling and misconstruing the information women receive) and intimidation (i.e., using their social authority to silence dissent and make their view the norm). Also, we see this obstetrical practice is based more on oppressive gender norms than sound empirical evidence. In this way, it parallels the attitudes toward women expressed by abusive men concerning women's proper role or place.

\section{COURT-ORDERED MEDICAL TREATMENT}

In the case of alcohol use during pregnancy, physicians manipulate information in an attempt to control women's behavior. In the case of court-ordered medical treatment, obstetricians use the power of the state to keep women under medical surveillance and/or perform medical treatments on behalf of the fetus against the woman's wishes. ${ }^{8}$ In this section, I show how this behavior also bears a disturbing likeness to the behavior of abusive men. In fact, I argue that forced medical treatment is a form of violence against women. ${ }^{9}$

Officially, ACOG supports a pregnant woman's right to refuse medical treatment and does not support the use of court-ordered medical interventions.

Pregnant women's autonomous decisions should be respected. Concerns about the impact of maternal decisions on fetal well-being should be discussed in the context of medical evidence and understood within the context of each woman's broad social network, cultural beliefs, and values. In the absence of extraordinary circumstances, circumstances that, in fact, the Committee on Ethics cannot currently imagine, judicial authority should not be used to implement treatment regimens aimed at protecting the fetus, for such actions violate the

7. For a recent analysis of the "good mother" narrative in relation to clinical and social practices, see Kukla (2008).

8. The physician in these cases is usually an obstetrician, but not always. For example, in the well-known Angela Carder case it was the hospital administrators who invoked judicial authority (Daniels 1993). However, most research on court-ordered medical treatment focuses on obstetricians and their attitudes; thus, I too emphasize the obstetrician's role.

9. I am not the first to make this argument. For example, Nancy Rhoden takes a similar position: "The court has authorized an act of violence against the woman, even if the violence is obscured by her cowed compliance in the face of judicial power" (Rhoden 1987). 
pregnant woman's autonomy. (ACOG Committee on Ethics 2005, 9, emphasis added)

Despite this strong statement in favor of maternal choice, court orders are still being sought and implemented.

In March 2009, Samantha Burton was 25 weeks pregnant. After admission to Tallahassee Memorial Hospital with ruptured membranes and signs of premature labor, Dr. Jana Bures-Forsthoefel, her obstetrician, recommended Burton remain in the hospital on bed rest for the remainder of her pregnancy. Burton wanted to leave the hospital and seek a second opinion. Instead, her obstetrician alerted the State Attorney and a hasty court hearing was convened. The judge ordered Ms. Burton to remain in the hospital and to comply with any procedures (including a cesarean) that her physician thought necessary to protect the health and life of the fetus. Three days later, Dr. Bures-Forsthoefel performed a cesarean on Ms. Burton that resulted in a stillbirth (Kaczor 2010). ${ }^{10}$

I appreciate the dilemma faced by a caring obstetrician. ${ }^{11}$ Let's take the case of a court-ordered cesarean delivery. Here we have a woman in the middle of delivering a viable (and usually full-term) fetus. The obstetrician identifies a medical indication that poses a significant risk to this almost born child and possibly the mother as well. The obstetrician (relying on his or her professional skills) believes he or she can alleviate or at least significantly lessen this risk by performing an immediate cesarean. In this way, the obstetrician experiences moral distress-"knowing" the right thing to do, but not being able to do it. ${ }^{12}$ While I appreciate the angst an obstetrician in this situation might feel, once the obstetrician crosses the line from informing and encouraging to trying to force a woman to comply, then he or she is also expressing misogynistic attitudes that ultimately lead to violence against women (i.e., performing medical treatment against the woman's wishes).

It is well established that surgery without consent is a form of battery and assault-and cesareans are no exception. Similarly, the courts have argued in other cases that person A cannot be forced to undergo medical treatment for the sake of person B even if person B's life is at

10. Even though this case was overturned on appeal, it did not spare Ms. Burton the indignity of hospital confinement or the violence of a coerced cesarean. As stated in the appellate court opinion, "Here, Ms. Burton was involuntarily admitted to the hospital and, ultimately, required to undergo a cesarean section against her will. She suffered a significant deprivation of her physical liberty and personal freedom" (Abrams, David H. for Appellant and McCollum 2010).

11. In addition to the reasons I discuss here, obstetricians (or hospital administrators) also often pursue court-orders as a preventative measure because they fear lawsuits. However, as long as the obstetrician has a well-documented refusal of treatment, there is no reason to fear lawsuits. In fact, some argue that seeking court intervention can increase the possibility of medical mistakes that lead to lawsuits (Adams, Mahowald, and Gallagher 2003).

12. I use scare quotes here because medical knowledge is fallible so the obstetrician's view of the situation may not be accurate. stake. ${ }^{13}$ Yet we disregard both of these precedents in the case of pregnant women. Thus, we are not allowing pregnant women the same right to bodily autonomy as other competent adults. As Nancy Rhoden states in her discussion of these cases, "The court compromises its integrity in making these orders, because whether it realizes it or not, it is treating the woman as a means-a vehicle for rescuing an imperiled fetus-and not as an end in herself" (Rhoden 1987, 122) ${ }^{14}$ Most research shows that when obstetricians choose to request court orders, they are acting in the interest of the fetus. I say this for three reasons. First, most of the rationales given for forced medical treatment (e.g., fetal distress, diabetic noncompliance, placenta previa) relate to potential harm to the fetus. Granted, some of these pose a risk to the woman as well, but we do not force competent patients to receive treatment even when it is in their best interests, so the focus appears to be on the fetus. Second, in most of these court orders, the court temporarily grants custody of the fetus to the physician, hospital, or a stateappointed guardian. The new guardian then consents to treatment in the interest of the fetus. Third, in a 2002 survey (Adams, Mahowald, and Gallagher 2003), every obstetrician who pursued a court order listed "welfare of the fetus" as the reason (in cases of placenta previa they also noted "welfare of the woman").

Even though these intentions may seem benevolent, obstetricians need to realize the malicious effect of the decision to invoke state authority. ${ }^{15}$ Court orders to perform medical interventions are used to override an autonomous woman's informed consent. ${ }^{16}$ The obstetrician believes he or she knows what choice a woman should make and seeks the ability to control what the pregnant woman does with her body. As such, forced cesarean sections (and other invasive procedures) are direct assaults on women's bodies. In this way, obstetricians who seek court orders use intimidation (i.e., medical authority), power (i.e., a court order and the threat of coercion that implies), and ultimately

13. The case I am referring to is McFall v. Shrimp as discussed in "Cesareans and Samaritans" (Rhoden 1987).

14. Not only do obstetricians who request these orders make the same mistake, but they also commit the mistake of medical hubris. One of the reasons we insist on informed consent for medical procedures is because the practice of medicine is as much art as science. The medical indications that obstetricians are reacting to are based on statistical calculations of risk and benefit. We can never know how this particular situation will turn out or whether the physician has accurately assessed the risk in this case. Indeed, there are a number of cases where the woman avoids the court-mandated cesarean and vaginally delivers a healthy baby. For example, Irwin and Jordon recount two cases where a court order was issued based on placenta previa, but the woman vaginally delivered a healthy baby (Irwin and Jordan 1987).

15. Nancy Rhoden gives an excellent analysis of how good intentions (i.e., fetal protection) can lead to bad legal decisions that erode women's autonomy (Rhoden 1987).

16. Most of these cases do not question the woman's competence. In fact, if the women were deemed incompetent to make decisions based on normal clinical practice, the course of action would be some standard of substitute judgment, not a court order. 
violence (i.e., the actual cesarean or other treatment) to control women.

Thus, we see a parallel between obstetricians who seek court orders and physically abusive partners. In most cases of court-ordered treatment, the obstetrician has told a woman an emergency cesarean is necessary and she has refused to comply. Often her refusal is accompanied by an attempt to leave the hospital or otherwise remove herself from the obstetrician's control. In response, the obstetrician seeks state authority to coerce the woman into doing what the obstetrician wants. ${ }^{17}$ Compare this scenario to studies of domestic violence that show abusive men use violence to control women:

Batterers, more than nonviolent men, feel threatened by challenges to their authority and views, and they often react to such threats with violence. (Goodrum, Umberson, and Anderson 2001, 232)

From these studies and clinical experience with battered women, it has been theorized that male partners are threatened by loss of control over the relationship when women announce their decision to separate, and some men will stop at nothing to regain control, including femicide. (Campbell et al. 2007, 254)

We see a similar attitude in the case of Samantha Burton. Ms. Burton tried to remove herself from Dr. BuresForsthoefel's care. Instead of allowing her to do this or to seek a second opinion, Dr. Bures-Forsthoefel invoked state power to force Ms. Burton to remain under her control. Ultimately, this state power also allowed Dr. Bures-Forsthoefel to commit a direct assault on Ms. Burton by performing surgery on her without consent. In both cases, force is used to regain control over women. ${ }^{18}$

In sum, forced cesareans are a direct assault on women's bodies. Whenever an obstetrician seeks a court order to force a woman to undergo medical treatment on behalf of her fetus, we have an obstetrician participating in violence against women. Also, in this case, we can see certain parallels between the intentions of obstetricians who seek court orders and abusive men-namely, using violence to control women and adherence to oppressive gender norms (i.e., women do not have the same rights to bodily autonomy as men do).

\section{OBSTETRICIANS AS ALLIES}

Let me reiterate that I believe most obstetricians are committed professionals who genuinely care about women's health. However, my argument is that obstetricians need to

17. For a particularly chilling account, see Laura Pemberton's story of how she fled the hospital while a court order was being obtained, but later was escorted back to the hospital and forced to undergo a cesarean (Pemberton 2009).

18. Some might argue that this case is anomalous because we have a woman obstetrician forcing another woman to undergo treatment. However, this does not undermine my overall argument that courtordered medical treatment is a form of violence against pregnant women. reassess some specific obstetrical practices. ACOG recognizes that court-ordered medical treatment is a violation of women's autonomy. I have shown that it is not only a violation of women's autonomy, but an actual act of violence against women. As such, ACOG should take a stronger stand against this practice. Since court orders continue to be sought and implemented, ACOG should use its authority to see that obstetricians who participate in violence against women are properly sanctioned.

While forced medical treatment is the most egregious obstetrical practice, it is also (thankfully) the most rare. Obstetricians should also reflect on other practices that perpetuate violence against women in a less blatant way. The abstinence-only response to alcohol use during pregnancy is an attempt to coercively control women's behavior by manipulation (i.e., control of and misrepresentation of information) and intimidation (i.e., use of social authority to silence dissent and make social norms adhere to their position). I have also shown how this approach relies more on oppressive gender norms than empirical evidence. Again, my argument is that this practice shows a disturbing likeness to the behavior and tactics of abusive men insofar as it uses oppressive gender norms to justify coercive control of women's behavior.

My goal in this article is not to vilify the obstetrical community, but to draw attention to the implications of certain obstetrical practices. While improved screening and intervention practices are worthy goals, they only treat the symptom (i.e., immediate violence against women) and not the cause (i.e., misogyny and oppression). Obstetricians need to be aware of (and work to change) practices they participate in that directly and indirectly contribute to violence against women.

\section{REFERENCES}

Abrams, David H.for Appellant, and Bill for Appellee McCollum. 2010. Samantha Burton v State of Florida. First District, State of Florida. Available at: http:/ /opinions.1dca.org/written/

ACOG Committee on Ethics. 2005. Committee opinion number 321: Maternal decision making, ethics, and the law, 321. Washington, DC: American College of Obstetricians and Gynecologists.

Adams, S. F., M. B. Mahowald, and J. Gallagher. 2003. Refusal of treatment during pregnancy. Clinics in Perinatology 30(1): 127-140.

American Congress of Gynecologists and Obstetricians. 2008. ACOG news release: Alcohol and pregnancy: Know the facts. In ACOG [database online]. Available at: http://www.acog.org/ from_home/publications/press_releases/nr02-06-08-1.cfm (accessed April 5, 2010).

American Congress of Obstetricians and Gynecologists. 2010. ACOG violence against women. In ACOG [database online]. Available at: http://www.acog.org/departments/dept_web.cfm?recno $=17$ (accessed March 26, 2010).

Armstrong, E. M. 2003. Conceiving risk, bearing responsibility: Fetal alcohol syndrome $\mathcal{E}$ the diagnosis of moral disorder. Baltimore, MD: Johns Hopkins University Press. 
Campbell, J. C., N. Glass, P. W. Sharps, K. Laughon, and T. Bloom. 2007. Intimate partner homicide: Review and implications of research and policy. Trauma, Violence, \& Abuse 8(3): 246-269.

Chambliss, L. R., R. C. Bay, and R. F. Jones. 1995. Domestic violence: An educational imperative? American Journal of Obstetrics and Gynecology 172: 1035-1038.

Chez, R. A., and D. L. Horan. 1999. Response of obstetrics and gynecology program directors to a domestic violence lecture module. American Journal of Obstetrics and Gynecology 180: 496-498.

Daniels, C. R. 1993. At women's expense: State power and the politics of fetal rights. Cambridge, MA: Harvard University Press.

Frank, E., L. Elon, L. E. Saltzman, D. Houry, P. McMahon, and J. Doyle. 2006. Clinical and personal intimate partner violence training experiences of U.S. medical students. Journal of Women's Health 15(9): 1071-1079.

Gavaghan, C. 2009. You can't handle the truth: Medical paternalism and prenatal alcohol. Journal of Medical Ethics 35(5): 300-303.

Goodrum, S., D. Umberson, and K. L. Anderson. 2001. The batterer's view of the self and others in domestic violence. Sociological Inquiry 71(2): 221-240.

Hall, J. 2000. Canal town boys: Poor white males and domestic violence. Anthropology \& Education Quarterly 31(4): 471-485.

Horan, D. L., J. Chapin, L. Klein, L. A. Schmidt, and J. Schulkin. 1998. Domestic violence screening practices of obstetriciangynecologists. Obstetrics and Gynecology 92: 785-789.
Irwin, S., and B. Jordan. 1987. Knowledge, practice, and power: Court-ordered cesarean sections. Medical Anthropology Quarterly 1(3): 319-334.

Kaczor, B. 2010. Florida woman fights ruling that kept her in hospital. Associated Press Newswire, January 26, section Domestic News.

Kukla, R. 2008. Measuring mothering. International Journal of Feminist Approaches to Bioethics 1(1): 67, 90.

Lyerly, A. D., L. M. Mitchell, E. Mitchell Armstrong, L. H. Harris, R. Kukla, M. Kupperman, and M. O. Little. 2009. Risk and the pregnant body. Hastings Center Report 39(6): 34-42.

Parsons, L. H., D. Zaccaro, B. Wells, and T. G. Stovall. 1995. Methods of and attitudes toward screening obstetrics and gynecology patients for domestic violence. American Journal of Obstetrics and Gynecology 173: 381-387.

Pemberton, L. 2009. Laura Pemberton: Speaking on her experience of a court-ordered cesarean surgery. In National Advocates for Pregnant Women [database online]. September 10. Available at: http:/ / advocatesforpregnantwomen.org/issues/court_ordered_ interventions/laura_pemberton_speaking_on_her_experience_of_a_ courtordered_cesarian_surgery.php (accessed January 14, 2011).

Rhoden, N. K. 1987. Cesareans and samaritans. Law, Medicine, and Health Care 15(3): 118-125.

van Wormer, K., and A. R. Roberts. 2009. Death by domestic violence: Preventing the murders and murder-suicides. Westport, CT: Praeger. 